\title{
The Optimal Changing Frequency of Hospital Privacy Curtains Based on Contamination Rates: A Prospective Culture Study
}

\section{Chan Mi Lee}

Seoul National University College of Medicine

Hye Yeon Goh

Seoul National University Hospital

Hyo Yeon Lee

Seoul National University Hospital

\section{Young Rok Oh}

Seoul National University Hospital

\section{Wan Beom Park}

Seoul National University College of Medicine

Nam Joong Kim ( $\nabla$ molder@unitel.co.kr)

Seoul National University College of Medicine https://orcid.org/0000-0001-6793-9467

\section{Short report}

Keywords: hospital, environment, contamination

Posted Date: October 26th, 2020

DOl: https://doi.org/10.21203/rs.3.rs-93425/v1

License: (1) This work is licensed under a Creative Commons Attribution 4.0 International License.

Read Full License 


\section{Abstract}

To estimate contamination rates over time, we obtained cultures from 34 hospital privacy curtains and two control curtains over 8 weeks. If cultures revealed microorganisms over 2.5 colony forming unit $(\mathrm{CFU}) / \mathrm{cm}^{2}$, we defined the curtains as contaminated. The burden of microorganisms of control curtains remained under $0.2 \mathrm{CFU} / \mathrm{cm}^{2}$ over the study period. The cumulative contamination rate of hospital privacy curtains increased over time (15.6\% at week $2,37.0 \%$ at week 4 , and $55 \%$ at week 8$)$. Contamination rates showed a tendency to increase as the number of beds in a room increased. We suggest that hospital curtains should be changed every 4 weeks, or less if the number of beds is high.

\section{Background}

Hospital privacy curtains can be easily contaminated with microorganisms $(1-3)$. Contaminated curtains are a potential source of infection and an important reservoir for dissemination $(4,5)$. Several studies have revealed that hospital privacy curtains become contaminated within a short period of time $(6,7)$. Considering hospital curtains as potential sources of outbreak, it would be reasonable to recommend a protocol for regular changing frequencies. Guidelines for environmental infection control from the Centers for Diseases Control and Prevention suggest that privacy curtains should be disinfected or changed more frequently than surfaces with minimal hand contact (8). The objective of this study was to estimate the contamination rates of hospital curtains over time and determine the optimal changing frequency for hospital curtains based on contamination rates.

\section{Methods}

We collected 34 hospital privacy curtains from one intensive care unit (ICU) (five curtains) and six general wards (29 curtains). Of the 29 curtains from general wards, one was from a 2-bed room, four were from 4bed rooms, five were from 5-bed rooms, 16 were from 6-bed rooms, and three were from 7-bed rooms. We also collected two control curtains from meeting rooms where no patients or caregivers had direct contact. New laundered curtains were put in place at the baseline of this study. They were sampled at baseline, and at weeks 1, 2, 3, 4, 6, and 8. During the study period, the curtains were changed as determined by the healthcare workers who were caring for patients. We recommended changing curtains prior to week 8 if they became visibly contaminated, if curtain cultures revealed vancomycin-resistant enterococcus (VRE) or methicillin-resistant Staphylococcus aureus (MRSA), or after being used by patients from whom VRE or MRSA were isolated.

The patients' side and leading edge of curtains were cultured using Rodac plates (Synergy Innovation, Seongnam, South Korea). For each sample, the plate was pressed against the curtain for 30 seconds. Curtain cultures taken on subsequent weeks were carried out at the same height but lateral to the previous sampling site to avoid contamination during the previous culture procedure. Contact plates were incubated at $36.5^{\circ} \mathrm{C}$ for 48 hours and swab samples were streaked on blood agar plates (Synergy Innovation), C-VRE plates (Synergy Innovation) for VRE selection, and MRSA6 plates (Synergy Innovation) 
for MRSA selection. Plates were incubated for 48 hours at $36.5^{\circ} \mathrm{C}$ and colony forming units (CFUs) were counted. Contamination levels were determined by calculating $\mathrm{CFU} / \mathrm{cm}^{2}$ per plate. Previous research has suggested that bacteriologic standards for hospital surface hygiene based on standards used in the food industry (9). Because the United Kingdom uses $<2.5 \mathrm{CFU} / \mathrm{cm}^{2}$ for cleaning efficacy, we defined our contamination threshold according to this standard. If cultures revealed a contamination level $\geq$ $2.5 \mathrm{CFU} / \mathrm{cm}^{2}$, the curtain was considered contaminated, regardless of further culture results.

\section{Results}

Thirty-four hospital curtains and two control curtains were placed and cultured as described. A total of 14 hospital curtains were removed prior to week 8 . Out of 14 hospital curtains, seven were removed following various changing schedules of each ward, three due to isolation of VRE from curtain cultures, two due to isolation of MRSA from admitted patients, and two due to isolation of VRE from admitted patients. None of the curtains were removed due to visible contamination.

The contamination level of control curtains remained under $0.2 \mathrm{CFU} / \mathrm{cm}^{2}$ over the study period. Eleven hospital curtains exceeded the contamination threshold of $2.5 \mathrm{CFU} / \mathrm{cm}^{2}$ before week 8 . The cumulative rate of contaminated curtains increased during the study period $(15.6 \%$ at week $2,37.0 \%$ at week 4 , and $55 \%$ at week 8 ; Table 1). MRSA was isolated from neither control nor hospital curtains during the study period. VRE was not isolated from control curtains, but was isolated from $11.8 \%(4 / 34)$ of hospital curtains during the study period (two at week 2 , one at week 4, and one at week 6).

Table 1

Cumulative contamination rates of hospital privacy curtains

\begin{tabular}{|llllllll|}
\hline & Baseline & Week & Week & Week & Week & Week & Week \\
& & $\mathbf{1}$ & $\mathbf{2}$ & $\mathbf{3}$ & $\mathbf{4}$ & $\mathbf{6}$ & $\mathbf{8}$ \\
\hline No. of curtains evaluated & 34 & 34 & 32 & 31 & 27 & 22 & 20 \\
\hline No. of contaminated curtains & 0 & 3 & 5 & 9 & 10 & 11 & 11 \\
\hline $\begin{array}{l}\text { Cumulative contamination rate } \\
(\%)\end{array}$ & 0 & 8.8 & 15.6 & 29.0 & 37.0 & 50.0 & 55.0 \\
\hline
\end{tabular}

Among the five curtains in the ICU, none were contaminated above a threshold of $2.5 \mathrm{CFU} / \mathrm{cm}^{2}$. In contrast, out of 29 curtains in general wards, eleven (37.9\%) were contaminated. The contamination rates of curtains from 2-, 4-, 5-, 6-, and 7-bed rooms were $0 \%(0 / 1), 0 \%(0 / 4), 20 \%(1 / 5), 43.8 \%(7 / 16)$, and 100\% $(3 / 3)$, respectively.

\section{Discussion}

Our study revealed that the cumulative contamination rate of hospital privacy curtains increased over time compared with control curtains. Contamination rates showed tendency to increase as the number of 
beds in a room increased. Considering that contamination of hospital curtains is likely due to direct contact with patients, caregivers, and healthcare workers, the higher number of beds might have contributed to more contact and contamination.

Although there is no definite cutoff value for contamination levels in hospital environments, previous studies have used $2.5 \mathrm{CFU} / \mathrm{cm}^{2}$ to define a surface in a hospital environment as clean (10-12), and this value has also been used as a surface standard in healthcare and food sectors (13). Because previous research used $<2.5 \mathrm{CFU} / \mathrm{cm}^{2}$ as the hygiene criteria $(14,15)$, we also used this value for the contamination threshold. Contamination level thresholds for hospital privacy curtains, which are associated with an increase in the transmission of microorganisms to patients, are currently not well established. Further studies are required to determine thresholds for contamination levels.

There are currently no standards in place for the changing or cleaning frequencies of hospital curtains (8). We suggest that hospital curtains need to be changed or cleaned every 4 weeks because the cumulative contamination rate was more than $30 \%$, and almost $10 \%$ of hospital curtains tested positive for VRE at week 4. Based on the tendency for contamination rates to increase as the number of beds in a room increased, we also suggest that hospital curtains in rooms where the number of beds is high are changed or cleaned at least every 4 weeks.

This study had some limitations. First, seven curtains were removed prior to week 8 following various regular changing schedules in hospital wards. This was an observational study, and we did not intervene in the routine changing practices of hospital curtains. Second, we could not determine whether the contamination was directly from a colonized patient because we did not perform molecular analysis of contaminating microorganisms. Third, the number of hospital curtains investigated was too small to make definitive recommendations for changing frequency.

\section{Conclusion}

Hospital privacy curtains could be easily contaminated and are a potential source of healthcareassociated infections. We found that the contamination rate of hospital curtains increased over time and showed tendency to increase as the number of beds in a room increased. We suggest that hospital curtains need to be changed or cleaned at least every 4 weeks.

\section{Abbreviations}

CFU colony forming unit; ICU:intensive care unit; VRE:vancomycin-resistant Enterococcus; MRSA:methicillinresistant Staphylococcus aureus

\section{Declarations}


We thank our colleagues of infection control team in Seoul National University Hospital.

\section{Authors' contributions}

NJK, HYG and CML designed the study and wrote the manuscript. HYG, YRO and HYL collected the data. WBP analyzed and interpreted the data. All authors read and approved the final manuscript.

\section{Funding}

Not applicable.

\section{Availability of data and materials}

All data generated or analyzed during this study are included in this published article.

\section{Ethics approval and consent to participate}

This study was approved by the Institutional Review Board of Seoul National University Hospital (IRB no. H-2009-073-1157).

\section{Consent for publication}

Not applicable.

\section{Competing interests}

The authors have no competing interests.

\section{References}

1. Trillis F, 3rd, Eckstein EC, Budavich R, Pultz MJ, Donskey CJ. Contamination of hospital curtains with healthcare-associated pathogens. Infect Control Hosp Epidemiol. 2008;29(11):1074-6.

2. Woodard DR, Buttner M, Cruz P, Roeder J. Microbial contamination of privacy curtains in the emergency department of a metropolitan hospital. J Hosp Infect. 2018;100(3):e153-e4.

3. Klakus J, Vaughan NL, Boswell TC. Meticillin-resistant Staphylococcus aureus contamination of hospital curtains. J Hosp Infect. 2008;68(2):189-90.

4. Mahida N, Beal A, Trigg D, Vaughan N, Boswell T. Outbreak of invasive group A streptococcus infection: contaminated patient curtains and cross-infection on an ear, nose and throat ward. J Hosp Infect. 2014;87(3):141-4.

5. Das I, Lambert P, Hill D, Noy M, Bion J, Elliott T. Carbapenem-resistant Acinetobacter and role of curtains in an outbreak in intensive care units. J Hosp Infect. 2002;50(2):110-4.

6. Schweizer M, Graham M, OhI M, Heilmann K, Boyken L, Diekema D. Novel hospital curtains with antimicrobial properties: a randomized, controlled trial. Infect Control Hosp Epidemiol. 
2012;33(11):1081-5.

7. Ohl M, Schweizer M, Graham M, Heilmann K, Boyken L, Diekema D. Hospital privacy curtains are frequently and rapidly contaminated with potentially pathogenic bacteria. Am J Infect Control. 2012;40(10):904-6.

8. Sehulster L, Chinn RY, Cdc, Hicpac. Guidelines for environmental infection control in health-care facilities. Recommendations of CDC and the Healthcare Infection Control Practices Advisory Committee (HICPAC). MMWR Recomm Rep. 2003;52(RR-10):1-42.

9. Dancer SJ. How do we assess hospital cleaning? A proposal for microbiological standards for surface hygiene in hospitals. J Hosp Infect. 2004;56(1):10-5.

10. Ho YH, Wang LS, Jiang HL, Chang CH, Hsieh CJ, Chang DC, et al. Use of a Sampling Area-Adjusted Adenosine Triphosphate Bioluminescence Assay Based on Digital Image Quantification to Assess the Cleanliness of Hospital Surfaces. Int J Environ Res Public Health. 2016;13(6).

11. Boyce JM, Havill NL, Havill HL, Mangione E, Dumigan DG, Moore BA. Comparison of fluorescent marker systems with 2 quantitative methods of assessing terminal cleaning practices. Infect Control Hosp Epidemiol. 2011;32(12):1187-93.

12. Furlan MCR, Ferreira AM, da Silva Barcelos L, Rigotti MA, de Sousa AFL, Dos Santos Junior AG, et al. Evaluation of disinfection of surfaces at an outpatient unit before and after an intervention program. BMC Infect Dis. 2019;19(1):355.

13. Moore G, Griffith C. Problems associated with traditional hygiene swabbing: the need for in-house standardization. J Appl Microbiol. 2007;103(4):1090-103.

14. Mulvey D, Redding P, Robertson C, Woodall C, Kingsmore P, Bedwell D, et al. Finding a benchmark for monitoring hospital cleanliness. J Hosp Infect. 2011;77(1):25-30.

15. Malik RE, Cooper RA, Griffith CJ. Use of audit tools to evaluate the efficacy of cleaning systems in hospitals. Am J Infect Control. 2003;31(3):181-7. 